Louisiana State University

LSU Digital Commons

4-7-2017

\title{
Giant field-induced adiabatic temperature changes in In-based off- stoichiometric Heusler alloys
}

\author{
Sudip Pandey \\ Southern Illinois University Carbondale \\ Abdiel Quetz \\ Southern Illinois University Carbondale \\ Anil Aryal \\ Southern Illinois University Carbondale \\ Igor Dubenko \\ Southern Illinois University Carbondale \\ Mikhail Blinov \\ Lomonosov Moscow State University
}

See next page for additional authors

Follow this and additional works at: https://digitalcommons.Isu.edu/physics_astronomy_pubs

\section{Recommended Citation}

Pandey, S., Quetz, A., Aryal, A., Dubenko, I., Blinov, M., Rodionov, I., Prudnikov, V., Mazumdar, D., Granovsky, A., Stadler, S., \& Ali, N. (2017). Giant field-induced adiabatic temperature changes in In-based offstoichiometric Heusler alloys. Journal of Applied Physics, 121 (13) https://doi.org/10.1063/1.4979475 


\section{Authors}

Sudip Pandey, Abdiel Quetz, Anil Aryal, Igor Dubenko, Mikhail Blinov, Igor Rodionov, Valerii Prudnikov, Dipanjan Mazumdar, Alexander Granovsky, Shane Stadler, and Naushad Ali 


\section{Giant field-induced adiabatic temperature changes in In-based off-stoichiometric Heusler alloys}

Cite as: J. Appl. Phys. 121, 133901 (2017); https://doi.org/10.1063/1.4979475

Submitted: 14 September 2016 • Accepted: 17 March 2017 • Published Online: 03 April 2017

Sudip Pandey, Abdiel Quetz, Anil Aryal, et al.
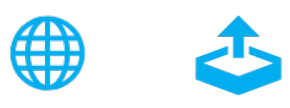

\section{ARTICLES YOU MAY BE INTERESTED IN}

Magnetic, transport, and magnetocaloric properties of boron doped Ni-Mn-In alloys Journal of Applied Physics 117, 183905 (2015); https://doi.org/10.1063/1.4921052

Magnetocaloric effect from indirect measurements: Magnetization and heat capacity Journal of Applied Physics 86, 565 (1999); https://doi.org/10.1063/1.370767

Large reversible magnetocaloric effect in $\mathrm{Ni}-\mathrm{Mn}-\mathrm{In}-\mathrm{Co}$

Applied Physics Letters 106, 021901 (2015); https://doi.org/10.1063/1.4905371

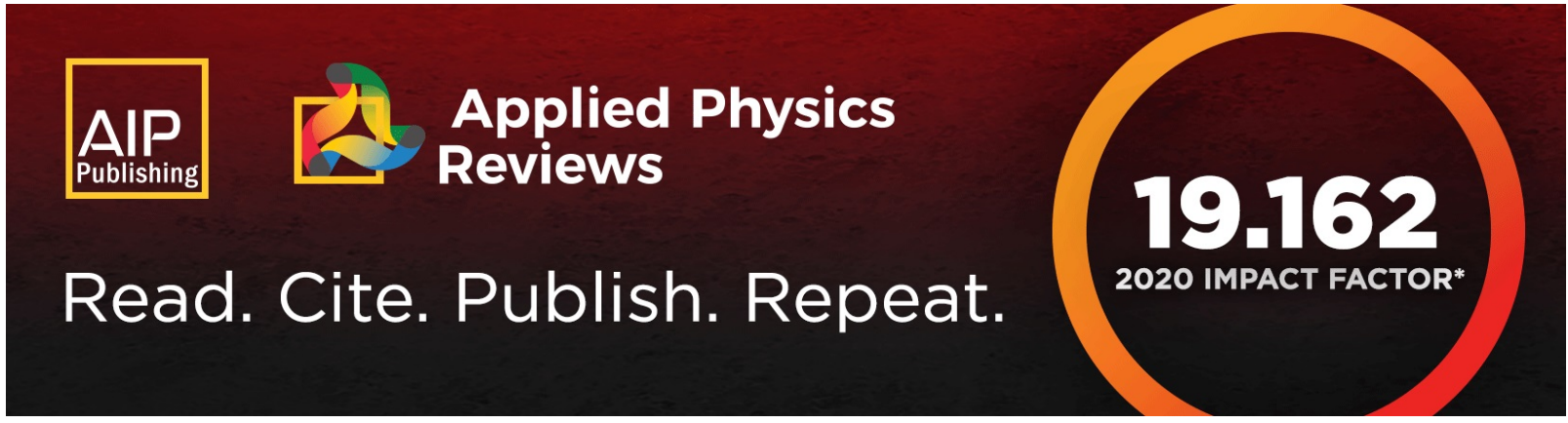




\title{
Giant field-induced adiabatic temperature changes in In-based off-stoichiometric Heusler alloys
}

\author{
Sudip Pandey, ${ }^{1}$ Abdiel Quetz, ${ }^{1}$ Anil Aryal, ${ }^{1}$ Igor Dubenko, ${ }^{1}$ Mikhail Blinov, ${ }^{2}$ Igor Rodionov, ${ }^{2}$ \\ Valerii Prudnikov, ${ }^{2}$ Dipanjan Mazumdar, ${ }^{1}$ Alexander Granovsky, ${ }^{2}$ Shane Stadler, ${ }^{3}$ \\ and Naushad Ali ${ }^{1}$ \\ ${ }^{1}$ Department of Physics, Southern Illinois University, Carbondale, Illinois 62901, USA \\ ${ }^{2}$ Faculty of Physics, Lomonosov Moscow State University, Moscow 119991, Russia \\ ${ }^{3}$ Department of Physics and Astronomy, Louisiana State University, Baton Rouge, Louisiana 70803, USA
}

(Received 14 September 2016; accepted 17 March 2017; published online 3 April 2017)

\begin{abstract}
Direct measurements of the adiabatic temperature change $\left(\Delta \mathrm{T}_{\mathrm{AD}}\right)$ of $\mathrm{Ni}_{50} \mathrm{Mn}_{35} \mathrm{In}_{14.5} \mathrm{~B}_{0.5}$ have been done using an adiabatic magnetocalorimeter in a temperature range of $250-350 \mathrm{~K}$, and with magnetic field changes up to $\Delta \mathrm{H}=1.8 \mathrm{~T}$. The initial susceptibility in the low magnetic field region drastically increases with temperature starting at about $300 \mathrm{~K}$. Magnetocaloric effects parameters, adiabatic temperature changes, and magnetic entropy changes were found to be a linear function of $\mathrm{H}^{2 / 3}$ in the vicinity of the second order transitions (SOT), whereas the first order transitions do not obey the $\mathrm{H}^{2 / 3}$ law due to the discontinuity of the transition. The relative cooling power based on the adiabatic temperature change for a magnetic field change of $1.8 \mathrm{~T}$ has been estimated. Maximum values of $\Delta \mathrm{T}_{\mathrm{AD}}=-2.6 \mathrm{~K}$ and $1.7 \mathrm{~K}$ were observed at the magnetostructural transition (MST) and SOT for $\Delta \mathrm{H}=1.8 \mathrm{~T}$, respectively. The observed $\Delta \mathrm{T}_{\mathrm{AD}}$ at the MST exceeds the $\Delta \mathrm{T}_{\mathrm{AD}}$ for $\mathrm{Ni}_{50} \mathrm{Mn}_{35} \mathrm{In}_{14} \mathrm{X}$ with $\mathrm{X}=\mathrm{In}, \mathrm{Al}$, and Ge by more than $20 \%$ and is larger than the Gd based Heusler alloys. Published by AIP Publishing. [http://dx.doi.org/10.1063/1.4979475]
\end{abstract}

\section{INTRODUCTION}

Magnetic materials are an important component of energy application development. Due to the continuous evolution of this field, new classes of magnetic materials are being discovered that have led to the emergence of new technologies, i.e., magnetic refrigeration. ${ }^{1,2}$ The off-stoichiometric Ni-Mn-In Heusler systems have been drawing interest due to their temperature-induced magnetostructural phase transitions that can produce large changes in magnetization and in related properties like giant normal and inverse magnetocaloric effects (MCE), ${ }^{3-5}$ giant magnetoresistance, ${ }^{6}$ Hall effects, ${ }^{7}$ and magnetic shape memory effects. ${ }^{8}$ Identifying the connection between these properties and their relationships to phase transition will help in better understanding the origins of magnetostructural transitions (MST), and to develop new materials for multifunctional applications.

It has been shown that the phase transitions of Ni-Mn-In based alloys with an In-concentration near $15 \%$ are extremely sensitive to small variations in composition..$^{9,10}$ It was reported that the temperature of the phase transitions and the magnetic state of the martensitic phases in $\mathrm{Ni}_{50} \mathrm{Mn}_{50-\mathrm{x}} \mathrm{In}_{\mathrm{x}}$ can be controlled through changing the $\mathrm{Mn} / \mathrm{In}$ ratio and therefore changing the conduction electron concentration (e/A ratio). ${ }^{11}$ Also, Gottschall et al. found the large reversible magnetocaloric effect in Co doped Ni-Mn-In alloys. ${ }^{12}$ Recently, it has been shown that the temperature at the MST strongly depends on the crystal cell volume and on the distortion in the local atomic environment in Ni-Mn-In based alloys. ${ }^{13}$ Thus, their magnetic and structural properties strongly depend on the stoichiometry and chemical composition. ${ }^{14,15}$

It was found that the adiabatic temperature change at the first-order structural phase transition temperature $\left(T_{M}\right)$ is about $\Delta \mathrm{T}_{\mathrm{AD}}=-3 \mathrm{~K}$ for $\mathrm{Ni}_{50} \mathrm{Mn}_{34} \mathrm{In}_{16}$ and $\mathrm{Ni}_{50} \mathrm{Mn}_{34} \mathrm{In}_{14} \mathrm{Ga}_{2}$ for a magnetic field change of $5 \mathrm{~T} .{ }^{16-18}$ Also, a $\Delta \mathrm{T}_{\mathrm{AD}}$ of about $1 \mathrm{~K}$ has been observed for both the first order transitions (FOT) and second order transitions (SOT) for a relativity small magnetic field change of $1 \mathrm{~T}$ for $\mathrm{Ni}_{50} \mathrm{Mn}_{35} \mathrm{In}_{14} \mathrm{X}(\mathrm{X}=\mathrm{In}, \mathrm{Al}$, and Ge) alloys. ${ }^{19}$ Most studies on the off-stoichiometric $\mathrm{Ni}_{50} \mathrm{Mn}_{35} \mathrm{In}_{15}$ Heusler alloys have been concentrated on determining the MCE parameters from isothermal magnetizations measurements at high magnetic fields. Here, we try to discover and study materials that show large field-induced adiabatic temperature changes at first and second order transitions, and at relatively low magnetic fields.

In this work, we have explored the influence of the isoelectronic substitution of B for In on the magnetic, thermal, and magnetocaloric properties of $\mathrm{Ni}_{50} \mathrm{Mn}_{35} \mathrm{In}_{15}$ Heusler alloys. We report the results of direct magnetocalorimetric measurements of $\Delta \mathrm{T}_{\mathrm{AD}}$ in the vicinity of the phase transitions of $\mathrm{Ni}_{50} \mathrm{Mn}_{35} \mathrm{In}_{14.5} \mathrm{~B}_{0.5}$ for applied magnetic field changes up to $1.8 \mathrm{~T}$.

\section{EXPERIMENTAL TECHNIQUES}

A $3 \mathrm{~g}$ polycrystalline ingot of $\mathrm{Ni}_{50} \mathrm{Mn}_{35} \mathrm{In}_{14.5} \mathrm{~B}_{0.5}$ was prepared by conventional arc-melting in a high-purity argon atmosphere using $4 \mathrm{~N}$ purity $\mathrm{Ni}, \mathrm{Mn}$, and In elements. The ingot was re-melted four times. For homogenization, the samples were annealed at $850^{\circ} \mathrm{C}$ for $48 \mathrm{~h}$ in high vacuum $\left(\approx 10^{-4} \mathrm{Torr}\right)$ and cooled at a rate of $4{ }^{\circ} \mathrm{C}$ per minute to room temperature. The crystal structure of the sample was studied using a room temperature X-ray diffractometer (XRD) employing $\mathrm{Cu}-\mathrm{K} \alpha$ radiation. The magnetic and magnetocaloric properties were measured using a Quantum Design superconducting quantum interference device magnetometer (Quantum Design, Inc.) in a 
temperature range of $10 \mathrm{~K}$ to $400 \mathrm{~K}$ and in magnetic fields up to $5 \mathrm{~T}$. Differential scanning calorimetry (DSC) measurements were carried out employing a Perkin-Elmer DSC 8000 instrument (with a ramp rate of $20 \mathrm{~K} / \mathrm{min}$ during heating and cooling) in the temperature range of $123-473 \mathrm{~K}$. Direct measurements of the adiabatic change of temperature, $\Delta \mathrm{T}_{\mathrm{AD}}$, under applied magnetic fields have been done using a magnetocalorimeter (MagEq MMS 801) in a temperature range of $250-350 \mathrm{~K}$, and in magnetic fields up to $1.8 \mathrm{~T}$. The external magnetic fields were ramped at a rate of up to $2 \mathrm{~T} / \mathrm{s}$ during the $\Delta \mathrm{T}_{\mathrm{AD}}$ measurements.

\section{RESULTS AND DISCUSSION}

The room temperature X-ray diffraction (XRD) pattern of $\mathrm{Ni}_{50} \mathrm{Mn}_{35} \mathrm{In}_{14.5} \mathrm{~B}_{0.5}$ is shown in Figure 1. At room temperature, the material is in a mixture of austenitic and martensitic phases, where the martensitic phase is in a tetragonal state. Only the traces of the high temperature austenitic phase (AP) were present. The XRD patterns from the austenitic phases were characterized by a low intensity of about $15 \%-22 \%$ that of martensitic phase. The XRD pattern is typical for Ni-Mn-In based Heusler alloys in the phase coexistence region exhibiting a MST near room temperature.

The zero-field-cooling ( $\mathrm{ZFC}$ ), field-cooling (FC), and field-cooled-cooling (FCC) magnetization $(\mathrm{M}(\mathrm{T})$ curves in a magnetic field of $0.01 \mathrm{~T}$ are shown in Figure 2(a). Before the ZFC measurement, the sample was cooled from room temperature to $5 \mathrm{~K}$ in a zero magnetic field. In the case of FCC measurements, the sample was cooled to $5 \mathrm{~K}$ in the presence of a 100 Oe magnetic field. The sample shows a splitting of the $\mathrm{ZFC}$ and $\mathrm{FC}$ magnetization curves at low temperature $(\mathrm{T}<170 \mathrm{~K})$. The splitting of the ZFC and FCC M(T) curves, observed slightly above the blocking temperature $\left(T_{B}\right)$, is evidence of exchange bias phenomena. ${ }^{20}$ Upon a further increase in temperature, the sample undergoes a transition at the Curie temperature of the martensitic phase $\left(\mathrm{T}_{\mathrm{CM}}\right)$, and the magnetization hits a minimum around $\mathrm{T}=255 \mathrm{~K}$. Further increasing the temperature, the sample passes from a low

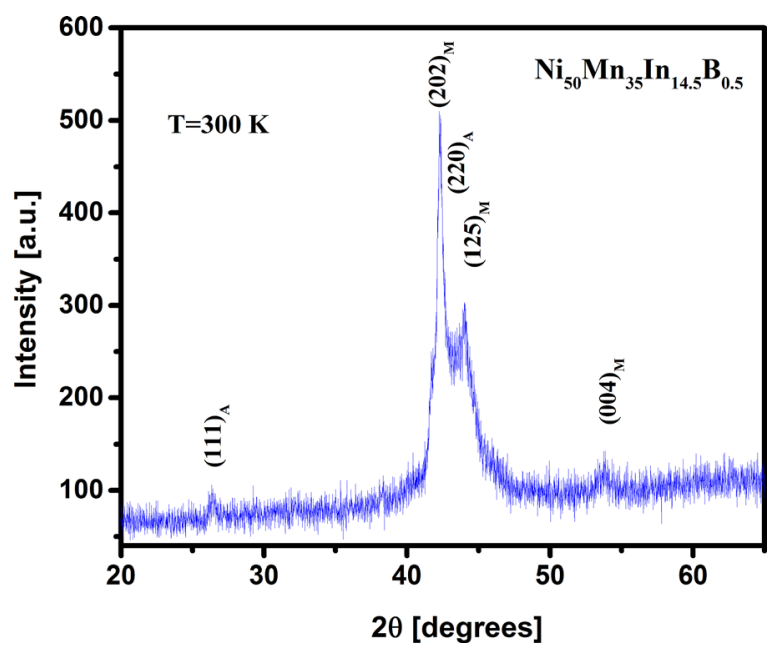

FIG. 1. Room temperature XRD pattern for $\mathrm{Ni}_{50} \mathrm{Mn}_{35} \mathrm{In}_{14.5} \mathrm{~B}_{0.5}$. The indexes of (hkl) for the martensitic and austenitic phases are represented by $\mathrm{M}$ and A, respectively.
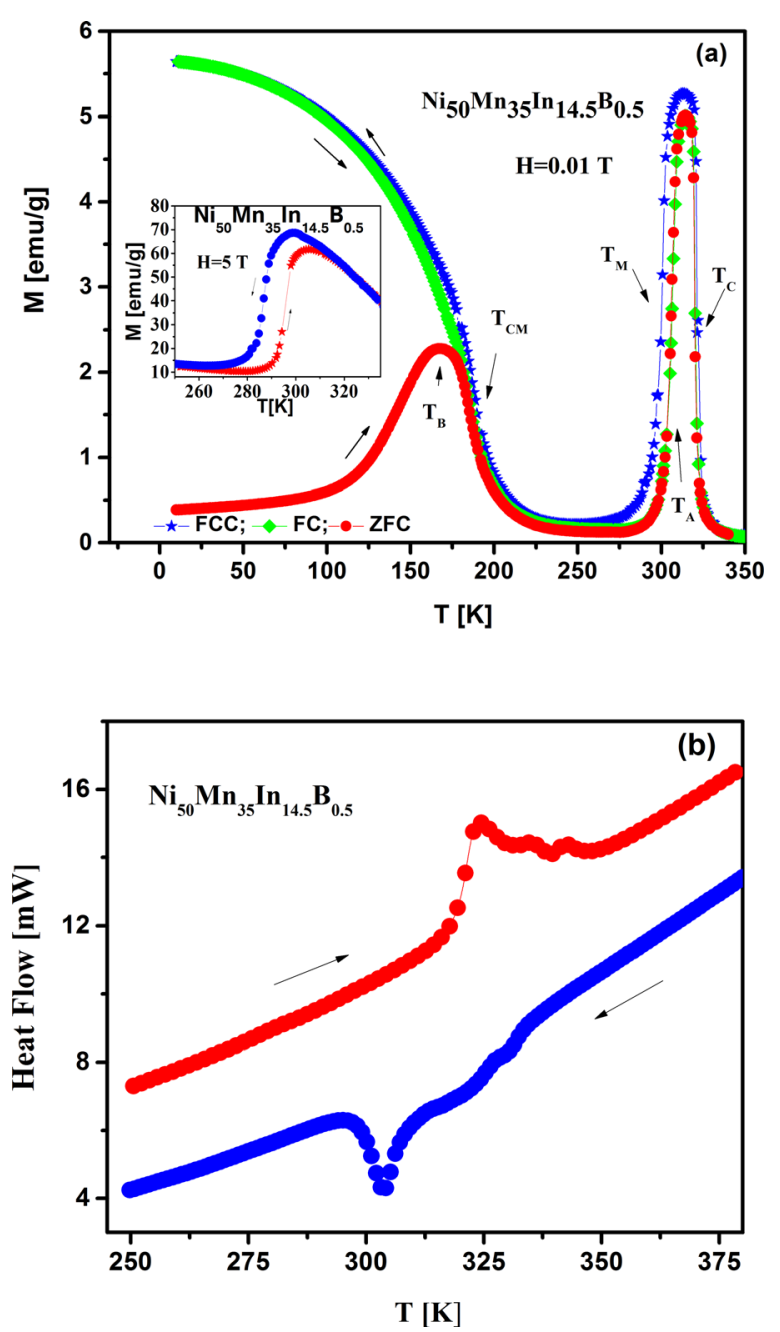

FIG. 2. (a) ZFC, FC, and FCC temperature-dependent magnetization curves

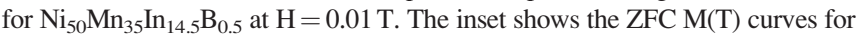
$\mathrm{Ni}_{50} \mathrm{Mn}_{35} \mathrm{In}_{14.5} \mathrm{~B}_{0.5}$ obtained at $\mathrm{H}=5 \mathrm{~T}$. (b) DSC heat flow curves as a function of temperature measured at a rate of $20 \mathrm{~K} / \mathrm{min}$ during heating and cooling.

magnetic moment state (antiferromagnetic (AFM) or paramagnetic (PM)) to a ferromagnetic (FM) austenitic state at the martensitic transition temperature $\mathrm{T}_{\mathrm{M}}=305 \mathrm{~K}$ and from a FM austenitic phase to a PM austenitic phase at the Curie temperature, $\mathrm{T}_{\mathrm{C}}=325 \mathrm{~K}$. The high field $(\mathrm{H}=5 \mathrm{~T}) \mathrm{ZFC} \mathrm{M}(\mathrm{T})$ data are shown in the inset of Figure 2(a). The maximum difference in magnetization, $\Delta \mathrm{M}$, at $\mathrm{T}_{\mathrm{M}}$ was found to be about $60 \mathrm{emu} / \mathrm{g}$ at $\mathrm{T}=290 \mathrm{~K}$ at $\mathrm{H}=5 \mathrm{~T}$. The maximum shift of temperature $\Delta \mathrm{T} \approx 14 \mathrm{~K}$ was observed for a magnetic field of $5 \mathrm{~T}$ which is responsible for the field-induced transition. ${ }^{21}$ The presence of hysteresis and the jump-like change in magnetization at $T_{M}$ are typical for first order structural (martensitic) transitions observed in these systems. The first-order MST was also observed in the DSC measurements which are shown in Figure 2(b). The well-defined endothermic/exothermic peaks, observed during heating/cooling cycles, are related to the latent heat of the first-order magnetostructural transition from the low magnetization state to the ferromagnetic structure. The temperature hysteresis of heat flow of about $18 \mathrm{~K}$ between heating and cooling cycles detected from DSC measurements is consistent with the magnetization results. 
Isothermal magnetization curves $\mathrm{M}(\mathrm{H})$ for $\mathrm{Ni}_{50} \mathrm{Mn}_{35}$ $\mathrm{In}_{14.5} \mathrm{~B}_{0.5}$ in the vicinity of the FOT and SOT are shown in Figure 3(a). The magnetization isotherms were found to be metamagnetic-like near the martensitic transition temperature and are characteristic of ferromagneticparamagnetic transitions near the Curie temperature. With increasing temperature, the critical field of the direct metamagnetic transition decreases. The large hysteresis was observed at $\mathrm{T}_{M}$ (hysteresis loops are represented by arrows in Figure 3(b)). The observed hysteresis near $T_{M}$ is a signature of a first order transition. Also, the initial susceptibility $(\mathrm{dM} / \mathrm{dH})$ in the low magnetic field region at Figure 3(a) drastically increases with temperature starting at $300 \mathrm{~K}$. The reason for the increase in the low field region is due to the presence of the ferromagnetic austenitic phase induced by temperature and magnetic field.

Field-induced entropy changes $\left(\Delta \mathrm{S}_{\mathrm{M}}\right)$ of $\mathrm{Ni}_{50} \mathrm{Mn}_{35}$ $\operatorname{In}_{14.5} \mathrm{~B}_{0.5}$ calculated from the $\mathrm{M}(\mathrm{H})$ isotherms (see Figure 3 ) are shown in Figure 4. The sample exhibits both inverse and direct magnetocaloric effects in the vicinity of the $\operatorname{MST}\left(\mathrm{T}_{\mathrm{M}}=301.5 \mathrm{~K}\right)$ and Curie temperature $\left(\mathrm{T}_{\mathrm{C}}=321.5 \mathrm{~K}\right)$,
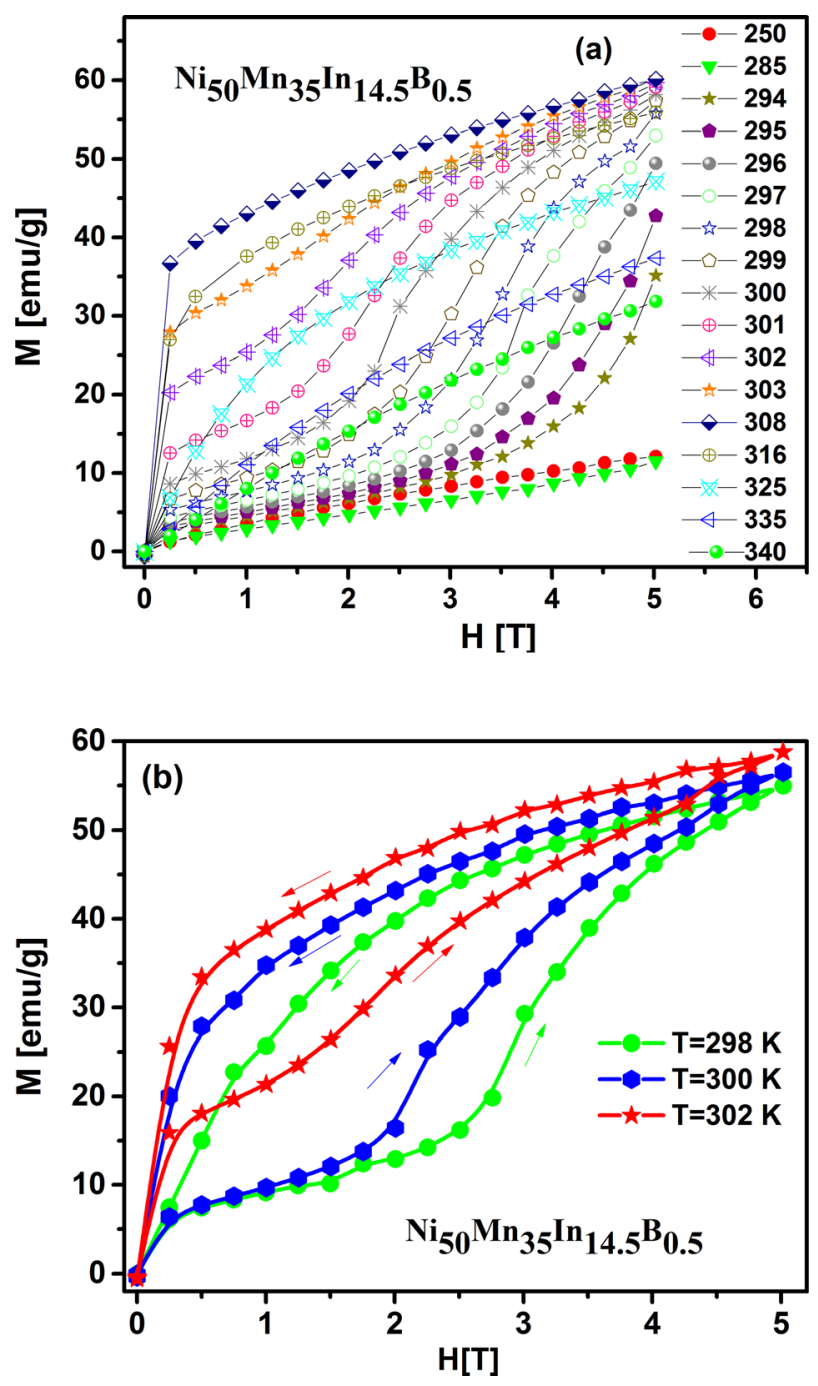

FIG. 3. (a) Magnetization isotherms of $\mathrm{Ni}_{50} \mathrm{Mn}_{35} \mathrm{In}_{14.5} \mathrm{~B}_{0.5}$ in the vicinity of $T_{M}$ and $T_{C}$. (b) The hysteresis loops in the vicinity of the first order transition for $\mathrm{Ni}_{50} \mathrm{Mn}_{35} \mathrm{In}_{14.5} \mathrm{~B}_{0.5}$.

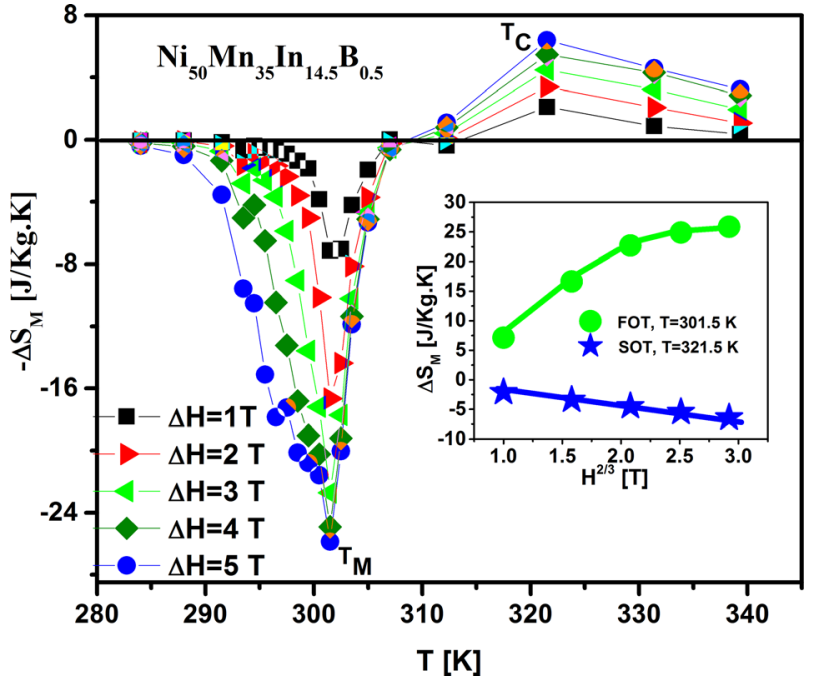

FIG. 4. Magnetic entropy change $\left(\Delta \mathrm{S}_{\mathrm{M}}\right)$ of $\mathrm{Ni}_{50} \mathrm{Mn}_{35} \mathrm{In}_{14.5} \mathrm{~B}_{0.5}$ in the vicinity of the FOT and SOT. The inset shows the maximum $\Delta \mathrm{S}_{\mathrm{M}}$ as a power function of magnetic field $\left(\mathrm{H}^{2 / 3}\right)$ collected at a given temperature $(\mathrm{T})$ in the vicinity of the FOT and SOT.

respectively. The maximum change in $\Delta \mathrm{S}_{\mathrm{M}}$ for applied magnetic fields of $5 \mathrm{~T}$ and $2 \mathrm{~T}$ are $\Delta \mathrm{S}_{\mathrm{M}}(5 \mathrm{~T})=26 \mathrm{~J} /(\mathrm{kg} \mathrm{K})$ and $\Delta \mathrm{S}_{\mathrm{M}}(2 \mathrm{~T})=18 \mathrm{~J} /(\mathrm{kg} \mathrm{K})$ for the MST, and $\Delta \mathrm{S}_{\mathrm{M}}(5 \mathrm{~T})=-6 \mathrm{~J} /$ $(\mathrm{kg} \mathrm{K})$ and $\Delta \mathrm{S}_{\mathrm{M}}(5 \mathrm{~T})=-3 \mathrm{~J} /(\mathrm{kg} \mathrm{K})$ for the SOT. These values of $\Delta \mathrm{S}_{\mathrm{M}}$ are comparable to other magnetocaloric materials that undergo martensitic transformations from low magnetic states to ferromagnetic austenitic phases. ${ }^{22}$

Another important parameter that is useful to evaluate the potential of an MCE material is the refrigeration capacity (RC). Magnetic hysteresis causes thermal losses at the FOT which reduces the RC. The estimated loss is calculated from the difference in area of $\mathrm{M}(\mathrm{H})$ curves obtained at field application and field removal at three characteristic hysteresis temperatures (see Figure 3(b)). The net RC is calculated by subtracting the average hysteretic loss from total RC. The net RC in the vicinity of FOT and SOT was found to be $90 \mathrm{~J} /$ $\mathrm{kg}$ and $170 \mathrm{~J} / \mathrm{kg}$ for a change of magnetic field $5 \mathrm{~T}$. It should be noted that the advantage of using materials with a large MCE at a SOT is the complete reversibility of the magnetization process. These values of RC are comparable to those of rare-earth-based systems near room temperature. ${ }^{23,24}$ The relative cooling power based on the adiabatic temperature change $(\mathrm{RCP})=\left(\Delta \mathrm{T}_{\mathrm{AD}}\right) \times\left(\delta \mathrm{T}_{\mathrm{FWHM}}\right)$ has also been calculated. The RCP for $\mathrm{Ni}_{50} \mathrm{Mn}_{35} \mathrm{In}_{14.5} \mathrm{~B}_{0.5}$ at a magnetic field of $1.8 \mathrm{~T}$ at $\mathrm{T}_{\mathrm{C}}$ and $\mathrm{T}_{\mathrm{M}}$ are $35 \mathrm{~K}^{2}$ and $11 \mathrm{~K}^{2}$, respectively.

The adiabatic temperature change $\left(\Delta \mathrm{T}_{\mathrm{AD}}\right)$ measurements were employed to directly assess the magnetocaloric effect. Although no cracks or crumbling was visible in the sample after the experiment, the $\Delta \mathrm{T}_{\mathrm{AD}}$ measurements had been carried out after two field cycles. The results of the direct measurement of $\Delta \mathrm{T}_{\mathrm{AD}}$ for $\mathrm{Ni}_{50} \mathrm{Mn}_{35} \mathrm{In}_{14.5} \mathrm{~B}_{0.5}$ are shown in Figure 5. Positive and negative changes in the sample temperature were found, as expected, in the presence of external magnetic fields in the vicinity of the SOT and FOT, respectively. The maximum absolute values of $\Delta \mathrm{T}_{\mathrm{AD}}=2.6 \mathrm{~K}$ and $1.7 \mathrm{~K}$ were measured at the MST and SOT for $\Delta \mathrm{H}=1.8 \mathrm{~T}$, respectively. As the FOT and SOT temperature ranges for 


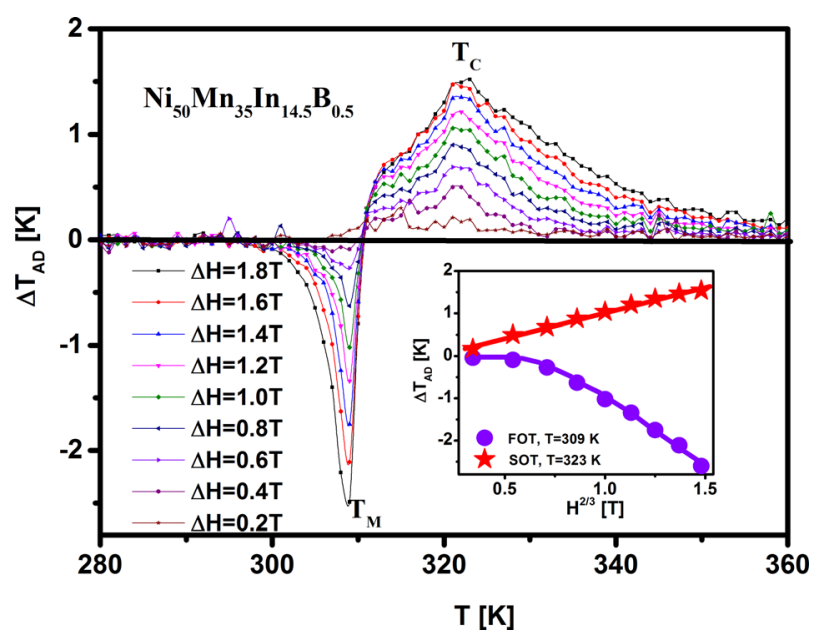

FIG. 5. Adiabatic temperature change $\left(\Delta \mathrm{T}_{\mathrm{AD}}\right)$ as a function of temperature for $\mathrm{Ni}_{50} \mathrm{Mn}_{35} \mathrm{In}_{14.5} \mathrm{~B}_{0.5}$ with $\Delta \mathrm{H}=1.8 \mathrm{~T}$. The inset shows the maximum $\Delta \mathrm{T}_{\mathrm{AD}}$ as a power function of magnetic field $\left(\mathrm{H}^{2 / 3}\right)$ collected at a given temperature (T) in the vicinity of the FOT and SOT.

this compound are not overlapping, ferromagnetic ordering in the austenitic phase (AP) is complete. Therefore, a larger difference in the magnetic order was observed which resulted in the larger $\Delta \mathrm{T}_{\mathrm{AD}}$. The $\Delta \mathrm{T}_{\mathrm{AD}}$ observed at the FOT was larger than that at the SOT. It is important to note that the $\Delta \mathrm{T}_{\mathrm{AD}}$ is free of hysteresis at the SOT, and there is no time dependence of $\Delta \mathrm{T}_{\mathrm{AD}}$ due to the SOT. Our direct measurements of $\Delta \mathrm{T}_{\mathrm{AD}}$ with the rate of changing magnetic field of $0.05-2.0 \mathrm{~T} / \mathrm{s}$ did not reveal any time dependence of $\Delta \mathrm{T}_{\mathrm{AD}}$ at the SOT. This value of $\Delta \mathrm{T}_{\mathrm{AD}}\left(\left|\Delta \mathrm{T}_{\mathrm{AD}}(\max )\right|=2.5 \mathrm{~K}, \Delta \mathrm{H}=1.8 \mathrm{~T}\right)$ observed at the MST exceeds the $\Delta \mathrm{T}_{\mathrm{AD}}$ observed for $\mathrm{Ni}_{50} \mathrm{Mn}_{35} \mathrm{In}_{14} \mathrm{X}$ ( $\mathrm{X}=\mathrm{In}, \mathrm{Al}$, and $\mathrm{Ge}$ ) by more than $20 \%$ (Ref. 19) and is larger than those of the Gd based Heusler alloys. ${ }^{25}$

From the molecular field theory and Landau's theory of phase transitions, both the magnetic entropy change and the adiabatic temperature change are linear functions of $\mathrm{H}^{2 / 3}$ in the vicinity of the SOT. ${ }^{26} \Delta \mathrm{T}_{\mathrm{AD}}$ and $\Delta \mathrm{S}_{\mathrm{M}}$ are plotted as a power function of magnetic field $\left(\mathrm{H}^{2 / 3}\right)$ collected at a given temperatures in the vicinity of the FOT and SOT in the inset of Figures 4 and 5, respectively. One can see that both $\Delta \mathrm{T}_{\mathrm{AD}}$ and $\Delta \mathrm{S}_{\mathrm{M}}$ are linear functions of $\mathrm{H}^{2 / 3}$ in the vicinity of the SOT, whereas FOT do not obey the $\mathrm{H}^{2 / 3}$ law due to the discontinuous transition. These observations are consistent with the theoretical results.

\section{CONCLUSION}

In conclusion, we used a magnetocalorimeter to directly measure the adiabatic temperature changes of $\mathrm{Ni}_{50} \mathrm{Mn}_{35}$ $\mathrm{In}_{14.5} \mathrm{~B}_{0.5}$ near their respective first and second order transitions. The magnetic properties and magnetocaloric effects have been systematically studied. The largest negative $\Delta \mathrm{T}_{\mathrm{AD}}$ was observed to be about $-2.6 \mathrm{~K}$ at the martensitic transformation for a field change of $1.8 \mathrm{~T}$. This value of $\Delta \mathrm{T}_{\mathrm{AD}}$ exceeds the $\Delta \mathrm{T}_{\mathrm{AD}}$ observed for $\mathrm{Ni}_{50} \mathrm{Mn}_{35} \mathrm{In}_{14} \mathrm{X}(\mathrm{X}=\mathrm{In}, \mathrm{Al}$, and $\mathrm{Ge}$ ) and Gd-based Heusler alloys. Thus, the larger values of $\Delta \mathrm{T}_{\mathrm{AD}}$ and other MCE parameters including $\Delta \mathrm{S}_{\mathrm{M}}, \Delta \mathrm{S}_{\mathrm{T}}$, and $\mathrm{RC}$ at lower magnetic fields make these compounds promising multifunctional material.

\section{ACKNOWLEDGMENTS}

This work was supported by the Office of Basic Energy Sciences, Material Science Division of the U.S. Department of Energy, DOE Grant Nos. DE-FG02-06ER46291 (SIU) and DE-FG02-13ER46946 (LSU). The author (A.B.G.) from Lomonosov Moscow State University acknowledges the support from the Russian Foundation for Basic Research (Grant No. 15-02-01976).

${ }^{1}$ E. Bruck, O. Tegus, D. T. Cam Thanh, N. T. Trung, and K. H. J. Buschow, Int. J. Refrig. 31, 763-770 (2008).

${ }^{2}$ K. G. Sandeman, Scr. Mater. 67, 566 (2012).

${ }^{3}$ A. O. Pecharsky, K. A. Gschneidner, Jr., and V. K. Pecharsky, J. Appl. Phys. 93, 4722 (2003).

${ }^{4}$ O. Tegus, E. Bruck, K. H. J. Buschow, and F. R. de Boer, Nature 415, 150 (2002).

${ }^{5}$ T. Krenke, E. Duman, M. Acet, E. F. Wassermann, X. Moya, L. Mañosa, and A. Planes, Nat. Mater. 4, 450 (2005).

${ }^{6}$ M. Khan, A. K. Pathak, M. R. Paudel, I. Dubenko, S. Stadler, and N. Ali, J. Magn. Magn. Mater. 320, L21 (2008).

${ }^{7}$ I. Dubenko, A. K. Pathak, S. Stadler, N. Ali, Ya. Kovarskii, V. N. Prudnikov, N. S. Perov, and A. B. Granovsky, Phys. Rev. B 80, 092408 (2009).

${ }^{8}$ K. Ullakko, J. K. Huang, C. Kantner, R. C. O. Handley, and V. V. Kokorin, Appl. Phys. Lett. 69, 1966 (1996).

${ }^{9}$ T. Samanta, A. Saleheen, D. L. Lepkowski, A. Shankar, I. Dubenko, A. Quetz, M. Khan, N. Ali, and S. Stadler, Phys. Rev. B 90, 064412 (2014).

${ }^{10}$ T. Takabatake, M. Shirase, K. Katoh, Y. Echizen, K. Sugiyama, and T. Osakabe, J. Magn. Magn. Mater. 177, 53-54 (1988).

${ }^{11}$ A. K. Pathak, M. Khan, I. Dubenko, S. Stadler, and N. Ali, Appl. Phys. Lett. 90, 262504 (2007).

${ }^{12}$ T. Gottschall, K. P. Skokov, B. Frincu, and O. Gutfleisch, Appl. Phys. Lett. 106, 021901 (2015).

${ }^{13}$ S. Pandey, A. Quetz, A. Aryal, T. Samanta, I. Dubenko, S. Stadler, and N. Ali, J. Appl. Phys. 117, 183905 (2015).

${ }^{14}$ I. Dubenko, A. Quetz, S. Pandey, A. Aryal, I. Rodionov, V. Prudnikov, E. Lahderanta, T. Samanta, A. Saleheen, S. Stadler, and N. Ali, J. Magn. Magn. Mater. 383, 186-189 (2015).

${ }^{15}$ S. Pandey, A. Quetz, A. Aryal, T. Samanta, I. Dubenko, S. Stadler, and N. Ali, J. Appl. Phys. 117, 17A737 (2015).

${ }^{16}$ S. Aksoy, T. Krenke, M. Acet, E. F. Wassermann, X. Moya, L. Manosa, and A. Planes, Appl. Phys. Lett. 91, 241916 (2007).

${ }^{17}$ A. M. Aliev, A. B. Batdalov, I. K. Kamilov, V. V. Koledov, V. G. Shavrov, V. D. Buchelnikov, J. García, V. M. Prida, and B. Hernando, Appl. Phys. Lett. 97, 212505 (2010).

${ }^{18}$ V. V. Khovaylo, K. P. Skokov, O. Gutfleisch, H. Miki, R. Kainuma, and T. Kanomata, Appl. Phys. Lett. 97, 052503 (2010).

${ }^{19}$ A. P. Kazakov, V. N. Prudnikov, A. B. Granovsky, A. P. Zhukov, J. Gonzalez, I. Dubenko, A. K. Pathak, S. Stadler, and N. Ali, Appl. Phys. Lett. 98, 131911 (2011).

${ }^{20}$ M. Khan, I. Dubenko, S. Stadler, and N. Ali, J. Appl. Phys. 102, 113914 (2007).

${ }^{21}$ R. Kainuma, Y. Imano, W. Ito, H. Morito, Y. Sutou, K. Oikawa, A. Fujito, K. Ishida, S. Okamoto, O. Kitakami, and T. Kanomata, Appl. Phys. Lett. 88, 192513 (2006).

${ }^{22}$ P. A. Bhobe, K. R. Priolkar, and A. K. Nigam, Appl. Phys. Lett. 91, 242503 (2007).

${ }^{23}$ A. Yucel, Y. Elerman, and S. Aksoy, J. Alloys Compd. 420, 182 (2006).

${ }^{24}$ M. H. Phan and S. C. Yu, J. Magn. Magn. Mater. 308, 325 (2007).

${ }^{25}$ K. A. Gschneidner, Jr., V. K. Pecharsky, and A. O. Tsokol, Rep. Prog. Phys. 68, 1479 (2005).

${ }^{26}$ H. Oesterreicher and F. T. Parkar, J. Appl. Phys. 55, 4334 (1984). 